\title{
A critical evaluation of diagnostic methods used to identify dairy cows with acute post-partum metritis in the current literature
}

\author{
Ines Sannmann, Sebastian Arlt and Wolfgang Heuwieser* \\ Clinic for Animal Reproduction, Faculty of Veterinary Medicine, Freie Universität Berlin, Berlin, Germany \\ Received 28 February 2012; accepted for publication 15 May 2012; first published online 11 September 2012
}

\begin{abstract}
The overall objective of this study was to investigate how relevant research publications address the validity of diagnostic methods for acute puerperal metritis (APM) in dairy cows, a disease commonly treated with antibiotic drugs. Therefore, a literature search was conducted in Journal of Dairy Science, Theriogenology, Animal Reproduction Science and The Veterinary Journal utilizing the ScienceDirect database. The search revealed 259 articles addressing APM. After applying exclusion criteria, a total of 48 trials remained. It was determined whether the author gave a clear definition of APM, the time of diagnosis relative to calving, and the person who performed the diagnosis. Studies were checked for the presence of definitions of possible findings, thresholds, and test characteristics of the methods used. Overall 9 different diagnostic methods were employed. On average $2 \cdot 5 \pm 1.75$ diagnostic methods were used in a study. References to support the use of the diagnostic methods were provided in 10 of 48 articles (20.8\%). Vaginal discharge, transrectal palpation and rectal temperature were examined in 39, 22, and 21 of the studies, respectively. Thresholds for diagnostic tests and test characteristics were mentioned in 6 and 3 of the 48 articles, respectively. Based on this systematic review of 48 research papers the evidence supporting the use of the diagnostic methods to identify cows with APM has either been not reported or is weak. In conclusion, the reporting of the diagnostic methods to identify cows with APM needs to be improved and further high-quality research is necessary to improve diagnostic performance of the methods employed.
\end{abstract}

Keywords: Acute puerperal metritis, dairy cow, diagnosis, literature.

Acute puerperal metritis (APM) is an acute systemic illness due to infection of the uterus, occurring within $21 \mathrm{~d}$ after parturition. The definition also includes an abnormally enlarged uterus and a fetid watery red-brown uterine discharge (Sheldon et al. 2006). These symptoms are associated with fever $\left(>39.5^{\circ} \mathrm{C}\right)$ and signs of systemic illness such as decreased milk yield, dullness or other signs of toxaemia, decreased dry matter intake, elevated heart rate, dehydration (Sheldon et al. 2009b). In studies applying these criteria, the incidence rate of APM was about 20\% (Drillich et al. 2001; Benzaquen et al. 2007; Dubuc et al. 2010). An older study reported an incidence rate of $40 \%$ (Markusfeld, 1987); however, the author did not provide a clear definition of APM.

It has been demonstrated that APM reduced feed intake, decreased long-term milk yield, and increased the chance of culling in multiparous but not primiparous cows (Dann et al. 2005; Dubuc et al, 2011; Wittrock et al. 2011). Most recently

*For correspondence; e-mail: w.heuwieser@fu-berlin.de the effect of APM on culling has been investigated in a study using 2178 cows in 6 herds in North America (Dubuc et al. 2011). Metritis did not have a direct effect on culling risk at 30 and $63 \mathrm{~d}$ in milk (DIM) or on the cumulative culling hazard up to 300 DIM. Reproductive diseases, however, made pregnancy less likely, which was a substantial risk factor for culling (Dubuc et al. 2011).

Substantial economic losses are incurred by reduced milk yield, culling and treatment costs. The total costs per case of metritis have been calculated to approximate to US\$ 329386 (Overton \& Fetrow, 2008). The reported incidence rates and the opportunity costs underline the importance of this disease. It is obvious that strategies for effective prevention, accurate and early diagnosis, and efficacious treatment of APM are essential. Antibiotic therapy has been adopted as a common treatment for metritis (Azawi, 2008). Today the systemic use of antibiotics is recommended by many authors (Drillich et al. 2001; LeBlanc et al. 2002; Sheldon \& Dobson, 2004). Most frequently used drugs for treatment of APM are penicillin, oxytetracycline, ampicillin and ceftiofur (Smith et al. 1998; Drillich et al. 2001; Currin, 2010). 
Table 1. Results of a literature search using the search criteria 'acute AND metritis' OR 'puerperal AND metritis' AND 'dairy cow' conducted in 4 journals (Journal of Dairy Science, Theriogenology, The Veterinary Journal and Animal Reproduction Science) with an impact factor of $1 \cdot 7-2 \cdot 9$ considering specific exclusion criteria

Criteria

Total found

Reviews

Personal experiences

Meta-analyses

Questionnaires

Abstracts

Other species than cattle

Other diseases than APM

In-vitro studies or post-mortem evaluation

Acute puerperal metritis not primary research focus 2

Total excluded

Remaining articles

Antibiotic use is associated with selective pressure for the emergence of resistant bacteria, which underscores the importance of their prudent use (Fishman, 2006). More recently, several publications have addressed serious concerns regarding resistance in zoonotic pathogens (Tragesser et al. 2006; CVMP, 2009; Mann et al. 2011). Ceftiofur, a third generation cephalosporin, approved for the treatment of APM has been widely used in research trials (Zhou et al. 2001; Chenault et al. 2004; Drillich et al. 2007) and is a common treatment on commercial dairy farms. Advantages include demonstrated efficacy, a zero day withdrawal period for milk, and fewer group changes which are disruptive (Cook \& Nordlund, 2009; Schirmann et al. 2011). Multi-drug resistant Salmonella species have been associated with the usage of third generation cephalosporins in dairy cows and their function as a reservoir for these pathogens (Frye \& Fedorka-Cray, 2007). Third-generation cephalosporins are valued for treating serious infections in human medicine. As a result, the use of ceftiofur in dairy cows could be a potential threat to the ability to cure life-threatening infections in humans (Allen \& Poppe, 2002).

Particularly, rectal temperature and assessment of vaginal discharge have been recommended as screening tools to identify diseased animals. It is noteworthy, however, that there is a lack of science-based information on the value or significance of measuring rectal temperature as a diagnostic tool to identify infectious diseases in the post-partum period (Benzaquen et al. 2007). Sheldon (Sheldon et al. 2009a) pointed out that having no 'gold standard' for the diagnosis of uterine diseases complicates the measurement of sensitivity and specificity of clinical definitions. It is simply assumed that the diagnostic performance of these tests (i.e. sensitivity and specificity) is sufficient for field use. Improved diagnostics to identify the aetiology of infections and help direct therapy belongs to the multifactorial interventions to prevent emergence and further spread of antibiotic resistance (Fishman, 2006).

Therefore, the overall objective of this study was to investigate how relevant research publications address the validity of diagnostic methods for APM in dairy cows. Specifically we set out to determine the proportion of studies that (1) provide a concise definition for APM, (2) cite references to support the use of the selected diagnostic methods to identify cows with APM, and (3) discuss test characteristics of the diagnostic methods and possibility of errors.

\section{Materials and Methods}

A systematic literature search was conducted on 02 April 2011 utilizing the ScienceDirect search engine (www. sciencedirect.com) to find articles involving the diagnosis of acute metritis. The search terms 'acute AND metritis' OR 'puerperal AND metritis' OR 'postpartum AND metritis' AND 'dairy cow' were used for the search in all fields. The search was conducted for Journal of Dairy Science, Theriogenology, Animal Reproduction Science and The Veterinary Journal. The data range was set to all years. Retrieval and management of references was performed with Endnote (Version X4.0.2; Thomson Reuters EndNote, New York NY, USA).

Using these criteria, the search revealed 259 articles published in the 4 journals specified. After exclusion of meta-analyses $(n=1)$, reviews $(n=12)$, personal experiences $(n=32)$, abstracts $(n=9)$, questionnaires $(n=2)$ and data analysis $(n=8) 195$ articles remained. Of those, 40 publications were excluded because of other species than cattle $(n=11)$ and other diseases than acute metritis $(n=29)$ as defined previously (Sheldon et al. 2006). Post-mortem and in-vitro evaluations $(n=6)$ were likewise excluded. From the remaining 149 articles 48 were identified as addressing acute metritis as the main research topic and used for a systematic evaluation (Table 1). The other 102 publications did not address metritis in the primary research objective (e.g. considered metritis merely as a risk factor for another disease or reduced milk yield). 
Table 2. Evaluation of the description of diagnostic methods in 48 research articles from Journal of Dairy Science, Theriogenology, The Veterinary Journal and Animal Reproduction Science according to the STARD-checklist

Presencet or absenceł of description of

Implementation

Specification of materials and instruments together with their Instructions for use and specific measures in participants

t coded as yes

¥ coded as no

For the evaluation of the literature the focus was set on the diagnostic methods used to identify cows with APM. Specifically, we determined whether the author gave a concise definition of APM and cited a reference for the definition. Also the investigator (i.e. author, veterinarian, farm personnel, not specified) and the time of diagnosis relative to calving were recorded.

Furthermore, the number and type of diagnostic methods used to identify cows with APM including references were determined considering the presence of references provided. Each diagnostic method was checked individually for 4 criteria (description of implementation, the definition of possible findings, thresholds, and test characteristics, such as sensitivity, specificity and accuracy) according to the STARD checklist which consists of 25 items to improve the accuracy and completeness of reporting of studies of diagnostic accuracy (Smidt, 2003). Presence and absence of such information was coded with yes (1) and no (0), respectively (Table 2).

When multiple methods were used each one was evaluated individually. Furthermore, it was evaluated whether a certain combination of methods was defined and weighted in respect to the diagnostic performance.

Findings of the 48 assessed articles were documented with Excel (Microsoft Office 2010, Microsoft Deutschland $\mathrm{GmbH}$, Munich, Germany) and statistically analysed with SPSS (Version 19.0, SPSS Inc., Munich, Germany). Frequency distributions were calculated for the criteria specified. Combinations of diagnostic methods were summarized in a cross table.

\section{Results}

In Journal of Dairy Science, Theriogenology, The Veterinary Journal and Animal Reproduction Science 162, 55, 21 and 21 papers were published, respectively. According to the exclusion criteria 211 publications had to be withdrawn (Table 1). Therefore, a total of 48 articles were eligible for further analysis (Table 3 ).

In $25(52 \cdot 1 \%)$ papers the author provided a definition of APM. References for the definition were cited in 9 of those 25 publications (36.0\%). Most often Sheldon et al. (2006) was cited $(n=7)$, whereas Olson et al. (1986), Roberts et al.
(1986), Földi et al. (2006), Paisley et al. (1986) and Smith et al. (1998) were cited once each. In 3 publications (33.3\%) multiple citations for the definition of APM were listed.

The diagnosis of APM was performed by one of the authors $(n=19)$ or not specified in 29 publications $(60 \cdot 4 \%)$. In 10, 7 and 2 studies diagnosis had been conducted by the farm veterinarian $(20.8 \%)$, the farm personnel $(14.6 \%)$, and by farm personnel and the investigator together $(4 \cdot 2 \%)$, respectively. The time of diagnosis relative to calving was specified in $33(68 \cdot 8 \%)$ of the articles. In 2, 10 and 1 of these papers APM was diagnosed on days 3-6, days 6-10 and on day 14 post partum, respectively. In the remaining 20 papers the investigator conducted the diagnosis on multiple times from days $0-10$ after parturition.

The total number of diagnostic methods counted in the 48 publications was 124 (mean 2.6 $\pm 1 \cdot 6 \mathrm{sD}$; median $2 \cdot 5 \pm 1 \cdot 75$ IQR; minimum: 0; maximum: 7).

Overall 9 different diagnostic methods were used (Table 4). Most of the studies utilized a combination of 2-7 diagnostic methods to identify cows with APM. In 36 publications, more than 1 method had been used. In $23(64 \%)$ and $9(25 \%)$ publications it was described how the diagnostic methods were combined and the methods weighted within the combination, respectively. In the remaining 13 articles using more than 1 diagnostic criterion no information was provided on the combination or weighting of the diagnostic methods used to identify cows with APM.

In 34 of the 124 cases $(27 \cdot 4 \%)$ the implementation of the diagnostic methods was described. In $93(75.0 \%)$ and $22(17 \cdot 7 \%)$ of the cases possible findings and precise thresholds were defined. Test characteristics have been presented in only 3 cases $(2 \cdot 4 \%)$.

The diagnostic methods were referenced in 10 articles (20.8\%). Sheldon et al. (2006) and Dohmen et al. (1995) were cited 5 and 2 times, respectively (Fig. 1). Morrow et al. (1966), Studer \& Morrow (1978), Tennant et al (1968), Földi et al. (2006), Sheldon et al (2006), Urton et al. (2005) and Thomsen et al. (2007) were cited once in 4 articles. The remaining studies $(n=38 ; 79.2 \%)$ did not list any references for the diagnostic methods used.

Vaginal discharge has been assessed and classified in $39(81 \cdot 3 \%)$ of the studies. In 10 of these articles $(25 \cdot 6 \%)$ the authors provided specific information about their reasoning 
Table 3. Research articles $(n=48)$ from Journal of Dairy Science, Theriogenology, Animal Reproduction Science and The Veterinary Journal used for final evaluation

\begin{tabular}{|c|c|c|c|c|c|}
\hline Lead author & Year & Journalt & Lead- author & Year & Journal† \\
\hline Gustafsson & 1976 & Therio & Nocek & 2006 & JDS \\
\hline Johnson & 1981 & JDS & Benzaquen & 2007 & JDS \\
\hline Harrison & 1984 & JDS & Bobe & 2007 & ARS \\
\hline Harrison & 1986 & JDS & Drillich & 2007 & JDS \\
\hline Markusfeld & 1978 & JDS & Huzzey & 2007 & JDS \\
\hline Carson & 1988 & Therio & Garcia- Ispierto & 2007 & Therio \\
\hline El-Azab & 1988 & Therio & Watters & 2008 & JDS \\
\hline Slama & 1991 & Therio & Lopez- Gatius & 2008 & Therio \\
\hline Esteban & 1994 & JDS & Balough & 2009 & Therio \\
\hline Barton & 1996 & JDS & Cerri & 2009 & JDS \\
\hline Beckett & 1998 & JDS & Galvao & 2009 & JDS \\
\hline Smith & 1998 & JDS & Huzzey & 2009 & JDS \\
\hline Hirvonen & 1999 & Therio & Law & 2009 & JDS \\
\hline Ostergaard & 1999 & JDS & Lima & 2009 & JDS \\
\hline Loeffler & 1999 & JDS & Silvestre & 2009 & ARS \\
\hline Jirrotsma & 2000 & Therio & Galvao & 2010 & JDS \\
\hline Drillich & 2001 & JDS & Duboc & 2010 & JDS \\
\hline Kaim & 2003 & JDS & Ostergaard & 2010 & JDS \\
\hline Mateus & 2003 & ARS & Olson & 2011 & JDS \\
\hline Reist & 2003 & Therio & Santos & 2011 & JDS \\
\hline Mendelez & 2004 & JDS & Silvestre & 2011 & JDS \\
\hline Gröhn & 2004 & JDS & Dubuc & 2011 & JDS \\
\hline Dann & 2004 & JDS & Malinowski & 2011 & TVJ \\
\hline Urton & 2005 & JDS & Toni & 2011 & JDS \\
\hline
\end{tabular}

†ARS = Animal Reproduction Science, JDS=Journal of Dairy Science, TVJ=The Veterinary Journal, Therio= Theriogenology

Table 4. Distribution of methods utilized alone or in combination to diagnose acute puerperal metritis in dairy cattle considering 48 peerreviewed publications of 4 journals (Journal of Dairy Science, Theriogenology, The Veterinary Journal and Animal Reproduction Science) with an impact factors of $1 \cdot 7-2 \cdot 9$

\begin{tabular}{|c|c|c|c|c|c|c|c|c|c|c|c|c|}
\hline \multirow[b]{2}{*}{ Number } & \multirow{2}{*}{$\begin{array}{l}\text { Method } \\
\text { Type }\end{array}$} & \multirow{2}{*}{$\begin{array}{l}\text { Total } \\
\text { used }\end{array}$} & \multirow{2}{*}{$\begin{array}{l}\text { Used } \\
\text { alone }\end{array}$} & \multicolumn{9}{|c|}{ Combined with number } \\
\hline & & & & 1 & 2 & 3 & 4 & 5 & 6 & 7 & 8 & 9 \\
\hline 1 & Assessment of vaginal discharge & 39 & 4 & & 18 & 21 & 14 & 11 & 5 & 4 & 4 & 2 \\
\hline 2 & Transrectal palpation & 22 & 3 & 18 & & 10 & 9 & 5 & 3 & 2 & 3 & 1 \\
\hline 3 & Rectal temperature & 21 & 0 & 21 & 10 & & 6 & 10 & 3 & 4 & 4 & 0 \\
\hline 4 & $\begin{array}{l}\text { Discharge by gloved hand, } \\
\text { vaginoscopy or metricheck }\end{array}$ & 15 & 1 & 14 & 9 & 6 & & 3 & 4 & 1 & 2 & 0 \\
\hline 5 & General condition & 11 & 0 & 11 & 5 & 10 & 3 & & 2 & 3 & 2 & 0 \\
\hline 6 & Bacteriological examination & 5 & 0 & 5 & 3 & 3 & 4 & 2 & & 0 & 1 & 0 \\
\hline 7 & Milk yield & 4 & 0 & 4 & 3 & 4 & 1 & 3 & 0 & & 2 & 0 \\
\hline 8 & Blood parameters & 4 & 0 & 4 & 3 & 4 & 2 & 2 & 1 & 2 & & 0 \\
\hline 9 & Visual inspection & 3 & 1 & 2 & 1 & 0 & 0 & 0 & 0 & 0 & 0 & \\
\hline & & 124 & 9 & 79 & 52 & 57 & 39 & 36 & 18 & 16 & 18 & 3 \\
\hline
\end{tabular}

concerning the classification of vaginal discharge. In 31 of these studies $(79 \cdot 5 \%)$ specific findings indicative of a disease were defined. In $4(10 \cdot 2 \%)$ articles thresholds were quoted. Test characteristics were not mentioned in any of these studies.

Transrectal palpation has been used in 22 studies (45.8\%) in combination with other methods and in 3 studies as the only diagnostic test. Diagnostic performance of transrectal examination in practice has been described in one of
22 articles. In 16 of those papers specific findings were described. Test characteristics were described in one article; information on thresholds was not given.

Rectal temperature has been used to diagnose cows with APM in 21 of the publications (43. 8\%) in various combinations with other criteria. The implementation for measuring the rectal temperature has been described in 7 of the 21 publications $(33 \cdot 3 \%)$. In the majority of publications, findings $(n=17 ; 81 \cdot 0 \%)$ and thresholds $(n=16 ; 76.0 \%)$ were 

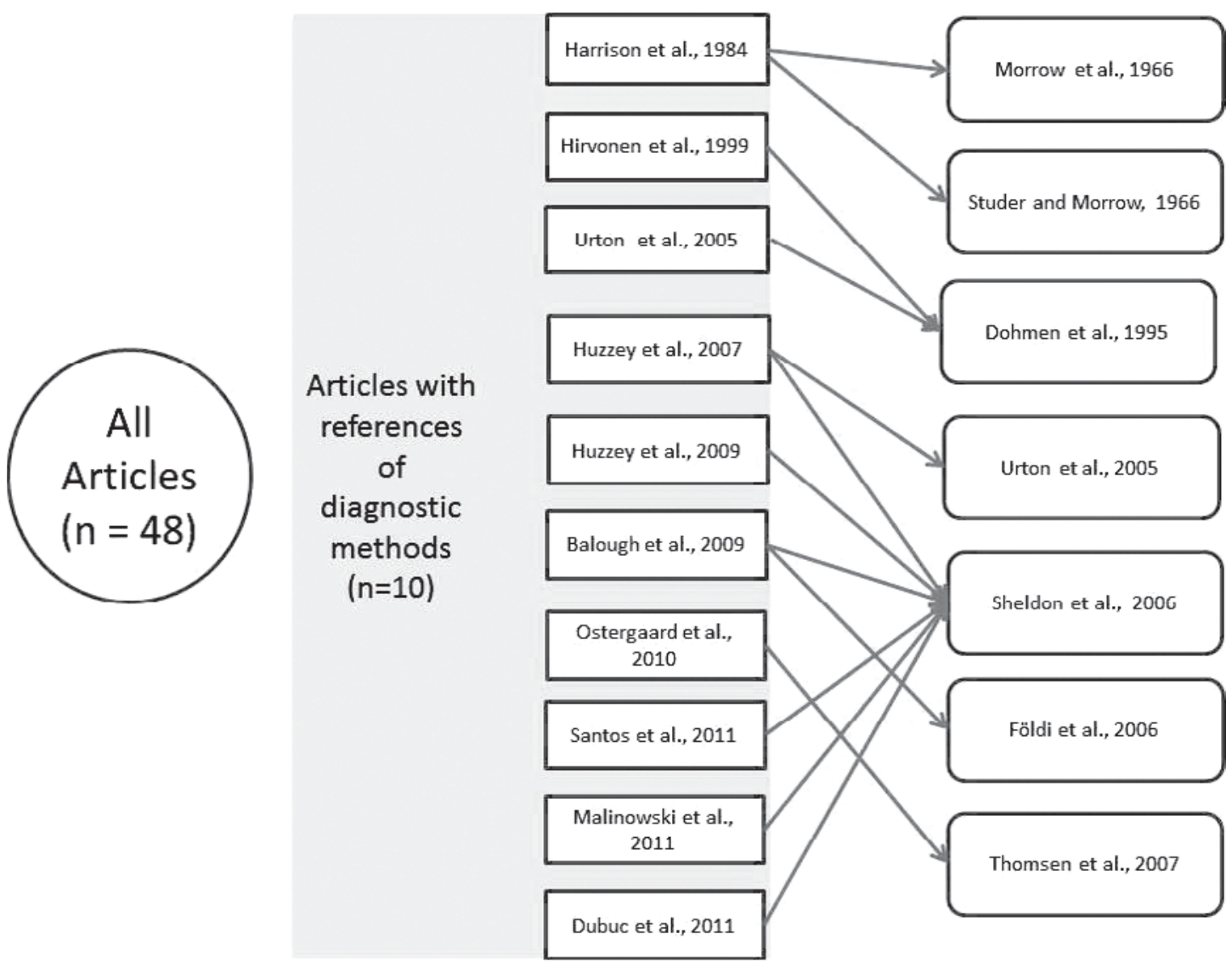

Fig. 1. Citation map showing the distribution of citations provided for the implementation of diagnostic methods for acute puerperal metritis.

provided. Data on test characteristics were completely missing.

Screening for vaginal discharge with a gloved hand, by vaginoscopy or the metricheck device has been conducted in 15 studies $(31.3 \%)$ in combination with other methods and in one study as the only diagnostic test. The implementation of using the gloved hand, a speculum or the metricheck device was described in 8 articles (53.3\%). Findings were specified in 10 out of 15 papers. A threshold for the diagnosis was described in one paper. Test characteristics were not stated.

The general condition of the cows examined has been used in $11(22.9 \%)$ studies. A quantitative scoring system was not described, but 8 articles provided a description of possible findings. Thresholds and test characteristics for evaluating the general condition of cows were not given.

In 5 studies a bacteriological examination has been conducted. The implementation was specified in 3 of those. In 2 of them outcomes were defined. Thresholds were not specified but test characteristics were provided in 1 publication.

A drop in milk yield in combination with other criteria was evaluated in 4 studies $(8 \cdot 3 \%)$. In all 4 publications the decrease has been specified. In none of the cases were data on thresholds or test characteristics provided.
In 4 studies $(8 \cdot 3 \%)$ blood parameters have been determined [haptoglobin $(n=4)$, fibrinogen $(n=1), \alpha 1$ glycoprotein $(n=1), \mathrm{N}$-acetyl- $\beta$-D-glucosaminidase activity $(n=1)]$ in combination with an evaluation of vaginal discharge, rectal temperature, and transrectal palpation of the uterus. In all 4 studies the sampling and analytical procedures have been described. In one study the results are missing. Thresholds and test characteristics have been provided in one article.

Visual inspection of the tail and perianal area has been used in 3 studies $(6 \cdot 3 \%)$. In one of them the inspection, conducted by the farm's veterinarian served as the only criterion to diagnose APM. Data on the diagnostic performance of visual inspection of the tail and perianal area has not been described by any of the authors. Descriptions of findings were specified in 2 articles. Thresholds and test characteristics were not given.

In 4 studies diagnosis of APM has been mentioned but the authors did not specify the methods.

\section{Discussion}

The overall objective of this study was to evaluate how relevant quality criteria of diagnostic methods to identify 
cows with APM are addressed in the current literature. Therefore we conducted a literature search in the Science Direct database considering Journal of Dairy Science, Theriogenology, Animal Reproduction Science, and The Veterinary Journal. These Journals have a special section or focus on animal reproduction and have impact factors of 1.72-2.79 (Reuters, 2011). This procedure generated a convenience sample but does not give a representative overview of all the literature published. One should be aware that using such a selection of journals may introduce a potential bias. Our goal, however, was to get a sample of research publications from peer-reviewed and high-quality journals that have a proven impact on management practices in the field of dairy reproduction and on future research. Our main research question was how intervention studies addressed quality criteria for diagnostic methods used during the trials. The focus was on clinical studies to generate information how the authors performed their diagnosis on APM in the field. Therefore, specific inclusion (e.g. cattle, metritis as main subject) and exclusion (e.g. meta-analyses, reviews, personal experiences) criteria were defined. Applying those criteria, 48 of 259 articles (18.5\%) were eligible for final analyses.

Recently several attempts have been made in the field of equine and canine medicine to systematically assess the evidence of certain intervention strategies (Fahie \& Shettko, 2007; Simoneit et al. 2011; Haimerl et al. 2012). Despite tremendous efforts the checklists used are prone to subjective interpretation, and inter-observer repeatability was only moderate. Therefore we assessed only distinct criteria that could be classified as present or absent (e.g. definition of APM, references for diagnostic procedures, test characteristics) or on a continuous scale (e.g. number of diagnostic methods used, days post partum when diagnosis was conducted). Therefore the results presented can be considered reproducible and objective.

In 4 of the $48(8 \cdot 3 \%)$ studies the diagnostic methods were not described at all. This constitutes a serious flaw that precludes valid conclusions. Authors of research publications should describe each intervention and diagnostic method thoroughly to allow a clinician wanting to use the intervention to know exactly how to perform the method used in the trial (Smidt, 2003; Glasziou et al. 2008). Only 10 articles $(20 \cdot 8 \%)$ cited references for the diagnostic methods utilized. According to the STARD checklist, the description should cover the full test protocol including the specification of materials and instruments together with their instructions for use, and specific measures in participants. If no citations are available, details must be provided in the text (Smidt, 2003). If this is not the case, it might be difficult to estimate the validity of the diagnostic methods used.

Frequently, the definition or characterization of the various manifestations of uterine disease either lack precision or definitions vary among research groups (Sheldon et al. 2006). Therefore, we evaluated whether the author gave a clear definition of the disease addressed in the study. Without a definition of a disease, it is hardly possible to distinguish between healthy and diseased cows, interpret test results, and provide recommendations for a larger population. Almost half of all articles, evaluated in our study did not provide such descriptions.

The diagnostic tests have been performed by one of the authors $(n=29)$, the farm veterinarian $(n=10)$, and by farm personnel $(n=7)$. One could speculate that the validity of a diagnosis is higher when performed by an animal health professional compared with farm personnel. At least we assume that the risk of an inaccuracy is higher, since the qualifications of the farm personnel to diagnose APM can differ widely. It is noteworthy that none of the studies evaluated an intra- or in case of multiple investigators an inter-observer repeatability of findings indicative of APM. Only very recently, first data on intra- and inter-observer variability on diagnostic methods relevant for the detection of APM were published (Burfeind et al. 2010; Leutert et al. 2012; Suthar et al. 2011)

APM usually occurs within $14 \mathrm{~d}$ after calving (Sheldon et al. 2006) and should therefore be diagnosed within this period. All of the authors, indicating the time of diagnosis $(n=33)$ were within this period. Since case definitions in the literature are highly confounded by diagnostic method and the interval post partum at which diagnosis is made (LeBlanc, 2008) a failure to report the time of diagnosis of APM constitutes a flaw that limits the evidence of the conclusions drawn.

Despite its frequent use the assessment of vaginal discharge has been discussed controversially in current literature. Vaginal discharge can be both a natural phenomenon after calving and a pathological condition (Lowder, 1993). Furthermore, the mere assessment of discharge without knowing where it comes from (i.e. vagina, cervix, and uterus) may not be reflective of endometrial inflammation. Cows with vaginal discharge might have cervicitis or vaginitis, but no endometrial inflammation (Dubuc et al. 2010). This limitation applies for the diagnosis of APM as well. On the other hand, the assessment of vaginal discharge has been described as an effective, simple and non-invasive method, especially for field use (LeBlanc et al. 2002; Sheldon et al. 2006; Pleticha et al. 2009). Also, a correlation between the type of discharge, the bacterial contamination of the uterus and the immune response of the diseased animal has been demonstrated (Williams et al. 2005).

After all, vaginal discharge by itself is a useful and important criterion to incorporate into a clinical examination (LeBlanc et al. 2002; Williams et al. 2005; Sheldon et al. 2006). Colour, smell and viscosity of vaginal discharge should be assessed (Sheldon et al. 2006). A description of these sensorial assessments was provided in 39 studies. Thresholds used to distinguish between healthy and diseased animals were not specified. Also, attempts were not described to objectify findings. In 4 articles, vaginal discharge was used as the only diagnostic criterion for APM without specifying how the discharge was obtained.

The second most commonly used diagnostic tool for APM was a transrectal palpation of the uterus $(n=22)$. Generally, 
this method is the most prevalent for the assessment of uterine infections (LeBlanc, 2008). It is well known, however, that transrectal palpation is a subjective method with limited sensitivity (Okano \& Tomizuka, 1987).

Frequently, rectal temperature was measured to diagnose APM. A high repeatability of rectal temperature measurements in dairy cows has been recently demonstrated (Burfeind et al. 2010). However, when rectal temperature is used as a diagnostic criteria, frequencies of both type I (fever when the animal is actually healthy) and type II errors (no fever when the animal is actually sick) are significant (Kristula et al. 2001; Sheldon \& Dobson, 2004; Wagner et al. 2007). A type I error causes financial losses to the producer since a healthy animal is unnecessarily treated. In case of APM an antibiotic drug would be used without need and selection pressure on pathogens exerted potentially contributing to the emergence of resistance. A type II error leaves a beneficial treatment effect on health and performance unrealized and might constitute an animal welfare issue, as the sick animal is not being treated and continues to suffer.

None of the 48 studies addressed the issue of sensitivity or specificity of rectal temperatures for the diagnosis of APM. Plausible factors (e.g. ambient temperature, parity) that can influence body temperature were discussed only in 2 papers. Also the time of the temperature measurements relative to calving varied from 1 to $21 \mathrm{~d}$ post partum.

Owing to these limitations fever has been considered less reliable than including an examination for abnormal uterine discharge because pyrexia is not consistently associated with pathogenic bacteria in the uterine lumen (Sheldon \& Dobson, 2004). In all 21 studies rectal temperature was used in combination with other diagnostic methods.

While the assessment of the general condition is recommended as part of a clinical examination (Jackson \& Cockcroft, 2002) it is a subjective criterion that is difficult to validate. External signs of toxaemia, potentially occurring in APM, are lacking enough accuracy since they do not appear constantly (Paleniki et al. 2009).

Four of 48 studies monitored milk yield as part of the APM diagnosis. A drop in milk yield can be observed from the first day of APM (Smith et al. 1998). However, it has also been observed that milk yield corresponds poorly with mild or subclinical conditions (Urton et al. 2005) and can even increase in cows with a mild fever (Rajala-Schultz et al. 1999).

In the past few years several papers discussed the diagnostic value of acute phase proteins as an indicator for APM (Smith et al. 1998; Regassa \& Noakes, 1999). A haptoglobin concentration $>10 \mathrm{mg} / \mathrm{dl}$ has been shown to indicate an acute infectious process in dairy cows and can support the diagnosis of APM (Hirvonen et al. 1999). Haptoglobin is particularly valuable in the early diagnosis of APM, because the concentration already increased $2 \mathrm{~d}$ before the clinical signs of APM were diagnosed (Huzzey et al. 2007). Furthermore, a relationship has been demonstrated between an elevated haptoglobin concentration and the bacterial contamination of the uterus (Williams et al.
2007). Haptoglobin is not specific for uterine infections, however, and therefore should not be used as a single diagnostic criterion for APM (Smith et al. 1998; Drillich et al. 2007).

Overall, 9 different methods for the diagnosis of APM were reported. Interestingly, none of the publications provided evidence or discussed whether the combination of methods increased the overall diagnostic performance to identify cows with APM.

For an ideal combination of diagnostic methods it is of interest to estimate their sensitivity and specificity. Ideally, each diagnostic procedure has a different property, leading to an increased overall sensitivity and specificity of the screening or diagnosis programme (Qin, 2010). Because a gold standard to verify inflammation of the uterus is lacking (Drillich et al. 2007), only few studies reported data on sensitivity and specificity and those that do reflect only a comparison of a new method with a reference method. Therefore it is impossible to determine a potential increase in sensitivity or specificity for a combination of methods. Only few authors $(n=7)$ discussed the diagnostic methods for APM and their possible limitations.

The most frequently cited paper has been authored by 4 internationally recognized experts in the field of uterine diseases (Sheldon et al. 2006). This paper provides current and probably the best evidence to support diagnostic methods for the detection of APM in dairy cows. The author's advice is to perform the diagnosis on the basis of clinical signs of illness and the assessment of vaginal discharge. A scoring system for APM has been recently developed (Sheldon et al. 2009b). Unlike the one for endometritis (Sheldon \& Dobson, 2004) this has not been consistently adopted yet for APM. Overall, our results clearly demonstrate that more high-quality research is necessary to better understand relationships between limitations of diagnostic methods and diagnostic and therapeutic errors.

Our findings encourage authors to explicitly describe implementation of diagnostic methods and to define possible findings, thresholds, and test characteristics or discuss the missing thereof. Practitioners and herd personnel should be aware of the potential of type I and type II errors. In some cases information on the magnitude of such errors is not available owing to the lack of a gold standard. It is obvious that more high-quality research is necessary to address issues related to APM and crucial to the dairy industry such as prudent use of antibiotics, animal welfare and financial costs.

\section{References}

Allen KJ \& Poppe C 2002 Occurrence and characterization of resistance to extended-spectrum cephalosporins mediated by $\beta$-lactamase CMY-2 in Salmonella isolated from food-producing animals in Canada. Canadian Journal of Veterinary Research 66 137-144

Azawi OI 2008 Postpartum uterine infection in cattle. Animal Reproduction Science 105 187-208 
Benzaquen ME, Risco CA, Archbald LF, Melendez P, Thatcher MJ \& Thatcher WW 2007 Rectal temperature, calving-related factors, and the incidence of puerperal metritis in postpartum dairy cows. Journal of Dairy Science 90 2804-2814

Burfeind O, von Keyserlingk MAG, Weary DM, Veira DM \& Heuwieser W 2010 Short communication: repeatability of measures of rectal temperature in dairy cows. Journal of Dairy Science 93 624-627

Chenault JR, McAllister JF, Chester T, Dame J, Kausche FM \& Robb EJ 2004 Efficacy of ceftiofur hydrochloride sterile suspension administered parenterally for the treatment of acute postpartum metritis in dairy cows. Journal of the American Veterinary Medical Association 224 1634-1639

Cook NB \& Nordlund KV 2009 The influence of the environment on dairy cow behavior, claw health and herd lameness dynamics. Veterinary Journal 179 360-369

Committee for Medicinal Products for Veterinary Use (CVMP) 2009 Revised reflection paper on the use of 3rd and 4th generation cephalosporins in food producing animals in the european union: Development of resistance and impact on human and animal health EMEA/CVMP/SAGAM/81730/2006

Currin J 2010 Management and prevention of metritis. Dairy Pipeline 31 1-2

Dann HM, Morin DE, Bollero GA, Murphy MR \& Drackley JK 2005 Prepartum intake, postpartum induction of ketosis, and periparturient disorders affect the metabolic status of dairy cows. Journal of Dairy Science 88 3249-3264

Dohmen MJW, Lohuis JACM, Huszenicza G, Nagy P \& Gacs M 1995 The relationship between bacteriological and clinical findings in cows with subacute/chronic endometritis. Theriogenology 43 1379-1388

Drillich M, Beetz O, Pfützner A, Sabin M, Sabin HJ, Kutzer P, Nattermann H \& Heuwieser W 2001 Evaluation of a systemic antibiotic treatment of toxic puerperal metritis in dairy cows. Journal of Dairy Science $\mathbf{8 4}$ 2010-2017

Drillich M, Voigt D, Forderung D \& Heuwieser W 2007 Treatment of acute puerperal metritis with flunixin meglumine in addition to antibiotic treatment. Journal of Dairy Science 90 3758-3763

Dubuc J, Duffield TF, Leslie KE, Walton JS \& LeBlanc SJ 2010 Risk factors for postpartum uterine diseases in dairy cows. Journal of Dairy Science 93 5764-5771

Dubuc J, Duffield TF, Leslie KE, Walton JS \& LeBlanc SJ 2011 Randomized clinical trial of antibiotic and prostaglandin treatments for uterine health and reproductive performance in dairy cows. Journal of Dairy Science $\mathbf{9 4}$ $1325-1338$

Fahie MA \& Shettko D 2007 Evidence-based wound management: a systematic review of therapeutic agents to enhance granulation and epithelialization. Veterinary Clinics of North America: Small Animal Practice 37 559-577

Fishman N 2006 Antimicrobial stewardship. American Journal of Medicine 119 S53-S61

Földi J, Kulcsár M, Pécsi A, Huyghe B, de Sa C, Lohuis JACM, Cox P, \& Huszenicza G 2006 Bacterial complications of postpartum uterine involution in cattle. Animal Reproduction Science 96 265-281

Frye JG \& Fedorka-Cray PJ 2007 Prevalence, distribution and characterisation of ceftiofur resistance in Salmonella enterica isolated from animals in the USA from 1999 to 2003. International Journal of Antimicrobial Agents 30 134-142

Glasziou P, Meats E, Heneghan C \& Shepperd S 2008 What is missing from descriptions of treatment in trials and reviews? British Medical Journal 336 1472-1474

Haimerl P, Arlt S \& Heuwieser W 2012 Evidence based medicine: Quality and comparability of clinical trials investigating the efficacy of prostaglandin F2 $\alpha$ for the treatment of bovine endometritis. Journal of Dairy Research 79 287-296

Hirvonen J, Huszenicza G, Kulcsàr M \& Pyörälä S 1999 Acute-phase response in dairy cows with acute postpartum metritis. Theriogenology 51 1071-1083

Huzzey JM, Veira DM, Weary DM \& von Keyserlingk MAG 2007 Prepartum behavior and dry matter intake identify dairy cows at risk for metritis. Journal of Dairy Science 90 3220-3233
Jackson PG \& Cockcroft PD 2002 The general clinical examination in cattle. In: Clinical Examination of Farm Animals. Blackwell Sciences Ltd, Oxford pp 9-11

Kristula M, Smith B \& Simeone A 2001 The use of dairy postpartum temperatures to select dairy cows for treatment with systemic antibiotics. Bovine Practitioners 35 117-125

LeBlanc SJ 2008 Postpartum uterine disease and dairy herd reproductive performance: a review. Veterinary Journal 176 102-114

LeBlanc SJ, Duffield TF, Leslie KE, Bateman KG, Keefe GP, Walton JS \& Johnson WH 2002 Defining and diagnosing postpartum clinical endometritis and its impact on reproductive performance in dairy cows. Journal of Dairy Science 85 2223-2236

Leutert C, von Krueger X, Plöntzke J \& Heuwieser W 2012 Evaluation of vaginoscopy for the diagnosis of clinical endometritis in dairy cows. Journal of Dairy Science 95 206-212

Lowder MQ 1993 Diagnosing and treating bovine postpartum endometritis. Veterinary medicine 88 474-479

Mann S, Siler JD, Jordan D \& Warnick LD 2011 Antimicrobial susceptibility of fecal Escherichia coli isolates in dairy cows following systemic treatment with ceftiofur or penicillin. Foodborne Pathogens and Disease 8 861-867

Markusfeld O 1987 Periparturient traits in seven high dairy herds. incidence rates, association with parity, and interrelationships among traits. Journal of Dairy Science 70 158-166

Morrow DA, Roberts S J, McEntee K \& Gray HG 1966 Postpartum ovarian activity and uterine involution in dairy cattle. Journal of the American Veterinary Medicine Association 1491596

Okano A \& Tomizuka T 1987 Ultrasonic observation of postpartum uterine involution in the cow. Theriogenology 27 369-376

Olson JD, Bretzlaff KN, Mortimer RG \& Ball L 1986 The metritispyometra complex. In: Current Therapy in Theriogenology: Diagnosis, treatment and prevention of reproductive diseases in small and large animals, 2nd Ed., W.B. Saunders Co., Philadelphia PA, USA, pp 227-236

Overton MW \& Fetrow J 2008 Economics of Postpartum Uterine Health Dairy Cattle Reproduction Council, Omaha NE, USA. November 7-8, 2008

Paleniki T, Dolezeli R, Kratochvilz J, Cechi S, Zajici J, Jani Z \& Vyskocil M 2009 Evaluation of rectal temperature in diagnosis of puerperal metritis in dairy cows. Veterinarni Medicina 54 149-155

Paisley LG, Mickelsen WD \& Anderson PB 1986. Mechanism and therapy for retained fetal membranes and uterine infections of cows: a review. Theriogenology 25 353-381

Pleticha S, Drillich M \& Heuwieser W 2009 Evaluation of the Metricheck device and the gloved hand for the diagnosis of clinical endometritis in dairy cows. Journal of Dairy Science $\mathbf{9 2}$ 5429-5435

Qin J \& Zhang B 2010 Best combination of multiple diagnostic tests for screening purposes. Statistics in Medicine 29 2905-2919

Rajala-Schultz PJ, Gröhn YT \& McCulloch CE 1999 Effects of milk fever, ketosis, and lameness on milk yield in dairy cows. Journal of Dairy Science 82 288-294

Regassa F \& Noakes DE 1999 Acute phase protein response of ewes and the release of PGFM in relation to uterine involution and the presence of intrauterine bacteria. Veterinary record 144 502-506

Reuters T 2011 Journal Citation Report http://thomsonreuters.com/

Roberts SJ 1986. Veterinary Obstetrics and Cenital Diseases. 3rd Ed. S.J. Roberts-Woodstock, NY, pp. 381-359

Schirmann K, Chapinal N, Weary DM, Heuwieser W \& von Keyserlingk MAG 2011 Short-term effects of regrouping on behavior of prepartum dairy cows. Journal of Dairy Science 94 2312-2319

Sheldon IM, Cronin J, Goetze L, Donofrio G \& Schuberth H-J 2009a Defining postpartum uterine disease and the mechanisms of infection and immunity in the female reproductive tract in cattle. Biology of Reproduction

Sheldon IM \& Dobson H 2004 Postpartum uterine health in cattle. Animal Reproduction Science 82-83 295-306

Sheldon IM, Lewis GS, LeBlanc S \& Gilbert RO 2006 Defining postpartum uterine disease in cattle. Theriogenology 65 1516-1530 
Sheldon IM, Williams EJ, Miller ANA, Nash DM \& Herath S 2009b Uterine diseases in cattle after parturition. Veterinary Journal 176 115-121

Simoneit C, Heuwieser W \& Arlt S 2011 Evidence-based medicine in bovine, equine and canine reproduction: quality of current literature. Theriogenology 76 1042-1050

Smidt N, Rutjes AWS, van der Windt DAWM, Ostelo RWJG, Bossuyt PM, Reitsma JB, Bouter LM \& de Vet HCW 2006 The quality of diagnostic accuracy studies since the STARD statement: Has it improved? Neurology 67 792-797

Smith BI, Arthur Donovan G, Risco C, Littell R, Young C, Stanker LH \& Elliott J 1998 Comparison of various antibiotic treatments for cows diagnosed with toxic puerperal metritis. Journal of Dairy Science $\mathbf{8 1}$ 1555-1562

Studer E \& Morrow DA 1978 Postpartum evaluation of bovine reproductive potential: Comparison of findings from genital tract examination per rectum, uterine culture and endometrial biopsy. Journal of the American Veterinary Medicine Association 172489

Suthar VS, Burfeind O, Bonk S, Voigtsberger R, Keane C \& Heuwieser W 2011 Factor associated with body temperature of healthy Holstein dairy cows during the first 10 days in milk. Journal of Dairy Research 87 1-8

Tennant B \& Peddicord RD 1968. The influence of delayed uterine involution and endometritis on bovine fertility. Cornell Veterinarian $\mathbf{5 9}$ 185

Thomsen PT, Ostergaard S, Sorensen JT \& Houe H 2007 Loser cows in Danish dairy herds: Definition, prevalence and consequences. Preventive Veterinary Medicine 79 116-135
Tragesser LA, Wittum TE, Funk JA, Winokur PL \& Rajala-Schultz PJ 2006 Association between ceftiofur use and isolation of Escherichia coli with reduced susceptibility to ceftriaxone from fecal samples of dairy cows. American Journal of Veterinary Research 67 1696-1700

Urton G, von Keyserlingk MAG \& Weary DM 2005 Feeding behavior identifies dairy cows at risk for metritis. Journal of Dairy Science $\mathbf{8 8}$ 2843-2849

Wagner SA, Schimeck DE \& Cend FC 2007 Body temperature and white blood cell count in postpartum dairy cows. Bovine Practitioner 42 18-26

Williams EJ, Fischer DP, Noakes DE, England GCW, Rycroft A, Dobson H \& Sheldon IM 2007 The relationship between uterine pathogen growth density and ovarian function in the postpartum dairy cow. Theriogenology 68 549-559

Williams EJ, Fischer DP, Pfeiffer DU, England GCW, Noakes DE, Dobson H \& Sheldon IM 2005 Clinical evaluation of postpartum vaginal mucus reflects uterine bacterial infection and the immune response in cattle. Theriogenology 63 102-117

Wittrock JM, Proudfoot KL, Weary DM \& von Keyserlingk MAG 2011 Short communication: Metritis affects milk production and cull rate of Holstein multiparous and primiparous dairy cows differently. Journal of Dairy Science 94 2408-2412

Zhou C, Boucher JF, Dame KJ, Moreira M, Graham R, Nantel J, Zuidhof S, Arfi L, Flores R, Neubauer G \& Olson J 2001 Multilocation trial of ceftiofur for treatment of postpartum cows with fewer. Journal of the American Veterinary Medical Association 219 805-808 